\title{
Social Conflict and Gradual Political Succession: An Illustrative Model*
}

\author{
William Jack \\ Georgetown University, Washington, DC 20057, USA \\ wgj@georgetown.edu
}

Roger Lagunoff

Georgetown University, Washington, DC 20057, USA

lagunofr@georgetown.edu

\begin{abstract}
This paper studies the evolution of political institutions in the face of conflict. We examine institutional reform in a class of pivotal mechanisms - institutions that behave as if the resulting policy were determined by a "pivotal" decision maker drawn from the potential population of citizens and who holds full policy-making authority at the time. A rule-ofsuccession describes the process by which pivotal decision makers in period $t+1$ are, themselves, chosen by pivotal decision makers in period $t$. Two sources of conflict-class conflict, arising from differences in wealth, and ideological conflict, arising from differences in preferences - are examined. In each case, we characterize the unique Markov-perfect equilibrium of the associated dynamic political game, and show that public decision-making authority evolves monotonically downward in wealth and upward in ideological predisposition toward the public good. We then examine rules-of-succession when ideology and wealth exhibit correlation.
\end{abstract}

Keywords: Political succession; political transitions; dynamic political games

JEL classification: D72; H41;C73; D74

\section{Introduction}

Institutional reform often occurs when policy reform cannot resolve conflict on its own. This paper studies the evolution of policy-making institutions in the face of social conflict. Our interest specifically is in pivotal mechanisms - institutions that behave as if the resulting policy were determined by a "pivotal" decision maker drawn from the potential population of citizens and who holds full policy-making authority at the time. The reform of a pivotal mechanism therefore describes the change effected by the delegation of authority from one decision maker to another. In other words, it is as

\footnotetext{
* We thank two anonymous referees for helpful comments and suggestions.

(C) The editors of the Scandinavian Journal of Economics 2006. Published by Blackwell Publishing, 9600 Garsington Road, Oxford, OX4 2DQ, UK and 350 Main Street, Malden, MA 02148, USA.
} 
if the individual empowered to make policy choices has the option of transferring his authority to another individual in the future. We identify such a transfer as a rule-of-succession.

In some historical cases, this as-if reasoning holds quite literally. For example, in monarchies, it was widespread practice for the current monarch to choose his successor. This was often true even when there were "exogenous" rules of monarchical succession. For instance, the historian Finer (1997, p. 483) writes of the Han dynasty in China (202 BC to 64AD):

"The succession was hereditary. In principle, the emperor could nominate
any of his sons as heir apparent; in practice this was complicated by the
fact of his having an enormous harem. It was for the emperor to designate
any one of his women as his empress, and it was usually understood that it
would be one of her sons who would be appointed crown prince. But this
simple rule broke down because, just as the emperor could create one of his
women as empress, so he could demote her and create another empress in her
place."

In more recent societies (and some ancient ones as well), the as-if reasoning also applies in voting institutions when the voting outcome coincides with the preferred choice of a pivotal voter. Black (1958), Roberts (1977), Grandmont (1978), Rothstein (1990), Gans and Smart (1996) and many others have derived conditions under which a Median Voter Theorem holds. In that case, it is as if a pivotal citizen (usually the median) in some well-defined linear ordering is the temporary "monarch" who can choose the current policy. This citizen's preference and wealth characteristics determine his vote, and hence the policy outcome. Where the present model is concerned, the multi-dimensional Median Voter Theorems of Roberts (1977), Grandmont (1978), Rothstein (1990) and Gans and Smart (1996) are of particular relevance since the current decision maker chooses both the current policy and the reform of the decision-making process.

Arguably, expansions of voting rights in nineteenth-century Europe can be usefully characterized this way. All over Western Europe, expansion of the franchise occurred. In England, the franchise expanded gradually: in 1830 , the voting franchise was restricted to $2 \%$ of the population, but through a series of gradual reforms, it expanded to universal suffrage by 1928; see Finer (1997) and Lang (1999). Holland and Belgium oversaw similar graduated expansions. In Italy in 1849, the voting franchise was granted to citizens above a wealth and educational threshold. The threshold on education was gradually reduced. In Prussia in the middle of the nineteenth century, voting was accorded proportionately to the percentage of taxes 
paid. Later the franchise was extended without qualification to all adult males. $^{1}$

The present paper asks whether social conflict, and its resolution, could lie at the heart of these historical examples of institutional change. In particular, our goal is to sort through the issues of modeling conflict and its effect on endogenous institutional choice. In this context, we study how the identities and characteristics of pivotal decision makers evolve in conflictual situations. Our results provide an explanation for why decision makers in modern societies (i) have lower relative wealth and (ii) want (or at least provide) more public goods than those of the past. ${ }^{2}$

Why do decision-makers' identities and characteristics change over time? The fundamental idea is that citizen heterogeneity naturally leads to disagreements over public policies. In turn, these disagreements lead to inefficient individual-level decision making and policy choices. The delegation of policy-making authority by a current policy maker to a new policy maker acts as a commitment device which improves the efficiency of these private decisions, even as it dilutes/eliminates the authority of the current policy maker.

Justman and Gradstein (1999), Acemoglu and Robinson (2000, 2001, 2006), Gradstein (2003), Lizzeri and Persico (2004) and Jack and Lagunoff (2006) all adopt the as-if approach to formally model enfranchisement and democratization as the result of redistributional conflict. In Acemoglu and Robinson (AR) conflict arises from the threat of insurrection by a group of disenfranchised "have-nots", who wish to dispossess the enfranchised "haves". They examine a model in which an elite makes a one-shot choice of whether to expand the voting franchise to the peasantry. In contrast to the externally driven explanation of AR, Lizzeri and Persico (2004) model the franchise expansion as an internal response to inefficiencies of political competition within the elite.

Because of the nature of their models, AR and Lizzeri and Persico do not address issues of gradual change. Gradualism arises in Roberts (1998, 1999) and Barbera, Maschler and Shalev (2001). Both examine dynamic club formation in games in which players have exogenous preferences over the size or composition of the group. These models examine endogenous entry into a group, though not endogenous voting

\footnotetext{
${ }^{1}$ The electorate was divided into three groups, each group given equal weight in the voting. The wealthiest group accounted for one-third of taxes paid but for only $3.5 \%$ of the population. The next wealthiest group accounted for another third of taxes and for $10-12 \%$ of the population. The poorest $85 \%$ made up the third group. See Finer (1997).

${ }^{2}$ Thanks to an anonymous referee for suggesting this characterization of the paper's contribution.
} 
rights per se. ${ }^{3}$ Gradualism in voting rights is formalized in Justman and Gradstein (1999), who characterize institutional change under exogenous costs of disenfranchisement, in Gradstein (2003) who examines choices over institutional quality, and in Jack and Lagunoff (2006) (henceforth JL) who study gradual franchise expansion in a recursive model that encompasses both external threats of insurrection and internal dissent amongst the elite. The present study expands on JL, but does not focus explicitly on the details of the aggregation mechanism-i.e. the details of either the voting procedure or the identity of enfranchised individuals. Instead, we assume there is a single decision maker (a dictator) in each period, and ask how his identity endogenously evolves.

Finally, Lagunoff $(2005 \mathrm{a}, \mathrm{b})$ posit a general model of a dynamic political game. Dynamic political games are games that admit dynamically endogenous choice from a broad array of institutions. These include changes in the voting rule (e.g. majority vs. supermajority rules), changes in the voting franchise, and expansions/contractions of regulatory authority.

The present model, which is a special case of a dynamic political game, examines the specific effects of class and ideological conflicts on political reform. In the first version of the model, wealth heterogeneity induces class conflict: in the context of tax-financed public goods, individuals with different wealth levels differ over their preferred tax rates. When individual efforts augment the productivity of public spending, non-cooperatively chosen tax policies and efforts will be inefficient. It is in the interest of the currently empowered to delegate policy-making authority to another agent with different preferences in order to elicit more desirable effort responses. Using specific functional forms, we construct the unique Markov-perfect equilibrium (MPE) in which decision-making power is delegated by one pivotal decision maker to the next in a monotonic fashion. Political evolution is "slow and steady" over time, and there is a downward rule of succession: authority is delegated to individuals with successively lower wealth endowment until (in the limit) policy is chosen by the poorest policy maker.

We do not argue that all or even most successions are, in fact, as slow and steady as the result suggests. Factors such as technological shocks and demographic shifts all might contribute to transfers that proceed in fits and starts. Our model nevertheless illustrates how the transfer of power proceeds when a form of class conflict is the primary source of change.

The second version of the model provides an example of ideological conflict. In this formulation, individuals have the same wealth, but differ

\footnotetext{
${ }^{3}$ The difference is that disenfranchised voters are still contributing, tax-paying members of society, while individuals who are excluded from a club do not contribute to the club until they enter. The differences account for quite distinct rationales for entry/enfranchisement.
} 
in their marginal valuations of a public good, such as state support for religion. As in the first example, the productivity of public spending on the public good is affected by citizens' effort levels. If decision-making authority initially rests with an individual who places a low value on the public good, then when authority is delegated to an individual with a higher valuation, all individuals are induced to supply efforts whose aggregate effect is preferred by the current policy maker. Indeed, we show that the MPE in this case exhibits an upward rule of succession.

A final version of the model combines both class and ideological conflict. We show that the rule-of-succession may be defined on a composite variable that describes the ratio of wealth to marginal valuation (ideology) for the public good. The MPE rule of succession is downward, in the sense that delegation proceeds toward those with successively lower wealth to valuation ratios. The dynamics converge to the lowest ratio in support of the distribution. However, if there is, as one would suspect, correlation between class and ideology, then this lowest ratio may still be consistent with high social class (large wealth endowment) or low marginal valuation.

While we do not present an explicit model of, say, the voting franchise, or of monarchical succession, we argue that many of the underlying forces that shape change under one type of institution are present in the other. For example, we can think of the public good as being the likelihood of political revolution, and voluntary contributions thereto reflect either support for the status quo or, when negative, support for overthrow. If the degree to which citizens wish to support either cause is correlated with their wealth, then political as well as policy reform may arise endogenously.

In the next section we present an illustrative model of public policy choice and public good provision that admits both class and ideological conflict. Section III examines the outcome of the dynamic political game associated with class conflict, and constructs a unique Markov-perfect equilibrium (MPE), characterized by a linear downward rule-of-succession. Section IV turns to an analysis of ideological conflict, in which we characterize a unique MPE that exhibits an upward rule-of-succession. Section V investigates the combined effects of these two sources of conflict, and Section VI concludes.

\section{An Illustrative Model}

We model an economy in which public goods provision depends on both involuntary taxation and voluntary contributions of time and/or effort by individual citizens. Conflicts over public policy - the level of taxation and public good provision - will arise if individuals differ either in their willingness to pay taxes, or in their valuation of the public good. Public goods that require both voluntary and involuntary contributions are unexceptional. For 
example, museums, universities, local fire-fighting services and national parks all utilize voluntary contributions. In many countries tax dollars help to fund an all-volunteer army. ${ }^{4}$ Public literacy campaigns and tax deductions for charitable contributions are further examples.

Consider then a society with $n$ infinitely lived citizens, $i=1,2, \ldots, n$. Time is discrete, and indexed by $t=0,1,2, \ldots$ Each citizen $i$ is endowed with an asset such as land that produces an exogenous flow of income $y_{i}>0$ each period. (Using the appropriate units, $y_{i}$ can also be used to measure the value of individual $i$ 's land holding.) Total per-period wealth is $Y=\sum_{i=1}^{n} y_{i}$. A proportional tax on wealth, whose rate $p_{t}$ is chosen in each period $t$, provides a source of public revenue $R_{t}=p_{t} Y$.

In addition to private wealth, individuals derive utility from a nondepreciable public good, the stock of which at date $t$ is denoted $\omega_{t}$. Increments to this public good in period $t+1$ are produced by combining tax revenues and voluntary contributions of labor effort on the part of citizens in period $t$. (Thus the "returns" to investment in the public good accrue with a one-period lag.) The effort of citizen $i$ in period $t$ is denoted $e_{i t}$, and the profile of efforts in period $t$ is $e_{t}=\left(e_{1 t}, e_{2 t}, \ldots, e_{n t}\right)$. Aggregate period $t$ effort is $E_{t}=\sum_{i=1}^{n} e_{i t}$, and the associated increment to the public good in period $t+1$ is $R_{t}^{\gamma} E_{t}$, with $0<\gamma<1$. We can interpret this production function as exhibiting decreasing returns to the tax-financed input, or as having constant returns but in an environment in which there is some "leakage" of public funds (e.g. through distortionary costs of taxation not directly modeled here). The accumulated stock of the public good at date $t$ is

$$
\omega_{t}=\sum_{s=0}^{t-1} R_{s}^{\gamma} E_{s}, \quad 0<\gamma<1 .
$$

In period $t$, each citizen $i$ cares about his after-tax wealth $y_{i}\left(1-p_{t}\right)$, his level of effort, $e_{i t}$, and the accrued value of the public good, $\omega_{t}$. The cost of effort (measured in units of income) is quadratic and the same for all individuals. On the other hand, the marginal rate of substitution between after-tax wealth and the public good, which is constant and equal to $\alpha_{i}$ for citizen $i$, can potentially differ across individuals. All citizens share the same discount rate $\delta<1$, and Citizen $i$ 's dynamic payoff is thus

$$
U_{i}=\sum_{t=0}^{\infty} \delta^{t}\left[\left(y_{i}\left(1-p_{t}\right)+\alpha_{i} \omega_{t}\right)-e_{i t}^{2}\right] .
$$

Because of the way current taxes influence future stocks of the public good, there is a clear trade-off between present income and future public good

\footnotetext{
${ }^{4}$ Though the soldiers may get nominal pay, it is typically not close to a market wage.
} 
consumption. Let $y$ and $\bar{y}$ denote the smallest and largest land endowments, and $\alpha$ and $\bar{\alpha}$ the smallest and largest values of $\alpha_{i}$, respectively. Consequently, $y_{i} \in[y, \bar{y}]$ and $\alpha_{i} \in[\underline{\alpha}, \bar{\alpha}]$ for all $i$.

According to the payoff in (2), there are two possible sources of heterogeneity. First, individuals potentially differ in land endowments, and hence incomes. Second, they may differ in their "ideology", that is, each may have distinct marginal valuation, $\alpha_{i}$, for the public good. These sources of heterogeneity present potential conflicts in each individual's view of the trade-offs between private and public consumption.

Ultimately, this conflict manifests itself in the choice of the tax rate, $p_{t}$. As an instrument of public policy, this rate is chosen by an authorized decision maker, whose authority derives from a political procedure that we leave unspecified for now. We argue that the most common political mechanisms feature such pivotal decision makers. Clearly, dictatorship and monarchy both place final decision-making authority in the hands of an individual. However, majoritarian rule also does so indirectly when policies are determined by the median voter. ${ }^{5}$

This individual, who we call the policy maker, is also permitted to appoint a different individual with policy-making authority in the subsequent period, thereby relinquishing power. In practice this individual is chosen from the existing citizenry, which is finite in number. As in JL05, however, for tractability we assume each subsequent decision-maker's type (as measured by $y$ or $\alpha$ ) is chosen by the current decision maker from a continuum, even though we maintain the assumption that only finitely many citizens make effort choices. ${ }^{6}$

We are interested in whether and when this option to relinquish governing power is exercised, and thus under what circumstances and to what degree political succession occurs.

Let $i_{t}^{*}$ denote the policy maker at date $t$. Let $y_{t}^{*}$ and $\alpha_{t}^{*}$ denote the land endowment and public good valuation, respectively, of this policy maker. The policy maker's preferences are given by

$$
V_{t}^{*}=\sum_{s=t}^{\infty} \delta^{s-t}\left[y_{t}^{*}\left(1-p_{s}\right)+\alpha_{t}^{*} \omega_{s}-e_{i_{t}^{*}}^{2}\right] .
$$

\footnotetext{
${ }^{5}$ Although there will be only one (or possibly two) individual(s) in the population as a whole with median preferences, the identity of the median voter can be altered by a suitable change in the franchise. Indeed, it would be possible to make the poorest individual the "median voter" by restricting the franchise to him alone-i.e., by making him a dictator.

${ }^{6} \mathrm{We}$ argue that the continuum is a reasonable approximation of a finite set of citizens when this set is uniformly and densely distributed in the continuum. However, if we were to assume a continuum of effort-making citizens, free-rider problems would be extreme, and equilibrium effort provision would be zero. With a finite number of citizens positive effort choices can be observed in equilibrium, and institutional evolution can affect these choices. See JL05 for a fuller discussion.
} 
In this context, "political succession" refers to the process of transition from policy maker $i_{t}^{*}$ at $t$ to a possibly different policy maker $i_{t+1}^{*}$ at date $t+1$. To understand how and why change might occur, and why it might be gradual, we explicitly model this "changing of the guard". As in JL, we consider the most direct method whereby $i_{t+1}^{*}$ is chosen by $i_{t}^{*}$. This model of succession also happens to be historically common, both in traditional monarchies, but also in democracies in which one political party is dominant. In this case, the current party boss chooses his successor directly. Postwar Japan and Mexico, for example, effectively had one-party rule until quite recently.

\section{Succession Based on Class Conflict}

We now consider the case of class conflict, assuming away ideological differences. Suppose all citizens differ only in land endowments, and are otherwise identical with $\alpha_{i}$ normalized to unity for all $i$.

Policy makers are also assumed to differ only by endowment. Their preferences in (3) also satisfy $\alpha_{t}^{*}=1$. For now we assume that $y_{t}^{*}$ can take any value in $[y, \bar{y}]$. That is, all policy makers' land endowments in the same range of land endowment as the citizenry. ${ }^{7}$ All citizens and all potential policy makers therefore value the public good the same way. However, land endowment heterogeneity induces differences in the way the trade-off between present income and future public goods consumption are viewed. Conflict is therefore driven by differences in social class.

Without loss of generality, associate each policy maker $i_{t}^{*}$ with his land endowment $y_{t}^{*}$. A policy maker $i_{t}^{*}$ therefore chooses pair $\left(p_{t}, y_{t+1}^{*}\right)$. There should be no confusion when we refer to $y_{t+1}^{*}$ as the successor of $y_{t}^{*}$. The initial policy maker has exogenous land endowment $y_{0}^{*}$.

To maximize his dynamic payoff, given by (2), an individual (either citizen and/or policy maker) chooses a strategy that determines a labor effort, a tax policy and a successor in each period. The choice in the current period $t$ is contingent on all past realizations $\left\{\left(e_{\tau}, p_{\tau}, y_{\tau+1}^{*}\right)\right\}_{\tau=0,1, \ldots, t-1}$. Subgame-perfect equilibria specify strategy profiles - profiles of mappings from histories to choices - that are sequentially rational after every possible history. Because the model is of a society rather than of a small group, we restrict attention to (stationary) Markov-perfect equilibria (MPE). MPE are subgame-perfect equilibria in Markov strategies whereby individuals condition their actions only on directly payoff-relevant and decision-relevant criteria. The restriction to Markov strategies is quite sensible for modeling

\footnotetext{
${ }^{7}$ For the purposes of the analysis, we do not care whether a policy maker is actually a citizen with a land endowment, or whether the policy maker is a social planner who acts as if his land endowment is $y_{t}^{*}$.
} 
behavior of large groups or societies since, in these instances, coordinated behavior on non-relevant features of a decision is unlikely.

In this present model, Markov strategies depend only on the land endowment, $y_{t}^{*}$, of the current policy maker. ${ }^{8}$

A Markov strategy in effort is given by $\sigma_{i}$ where labor effort $e_{i t}=\sigma_{i}\left(y_{t}^{*}\right)$ is chosen by Citizen $i$ given the state $y_{t}^{*}$. Let $\sigma=\left(\sigma_{1}, \ldots, \sigma_{n}\right)$. Similarly, $\psi$ is the Markov policy rule, i.e., tax rate $p_{t}=\psi\left(y_{t}^{*}\right)$ is chosen in state $y_{t}^{*}$. Finally, $\mu$ is the rule-of-succession, whereby $y_{t+1}^{*}=\mu\left(y_{t}^{*}\right)$ is the chosen successor of $y_{t}^{*}$.

A strategy profile $(\sigma, \psi, \mu)$ is an MPE if, in each state $y_{t}^{*}$, (i) for each citizen $i$, taking the strategies $\sigma_{j}(\cdot)$, (for $\left.j \neq i\right), \psi(\cdot)$ and $\mu(\cdot)$ as fixed, each $\sigma_{i}\left(y_{t}^{*}\right), i=1, \ldots, n$, constitutes a solution to that citizen's Bellman equation:

$$
\begin{aligned}
U_{i}\left(y_{t}^{*}\right)= & \max _{e_{i}}\left[y_{i}\left(1-\psi\left(y_{t}^{*}\right)\right)\right. \\
& \left.+\frac{\delta}{1-\delta}\left(\psi\left(y_{t}^{*}\right) Y\right)^{\gamma}\left(e_{i}+\sum_{j \neq i} \sigma_{j}\left(y_{t}^{*}\right)\right)-e_{i}^{2}\right]+\delta U_{i}\left(\mu\left(y_{t}^{*}\right)\right),
\end{aligned}
$$

and (ii) for the current policy maker, $\psi\left(y_{t}^{*}\right)$ and $\mu\left(y_{t}^{*}\right)$ jointly constitute a solution to his Bellman equation:

$$
\begin{aligned}
V_{t}^{*}\left(y_{t}^{*}\right)= & \max _{e_{i^{*}}, p_{t}, y_{t+1}^{*}}\left[y_{t}^{*}\left(1-p_{t}\right)+\frac{\delta}{1-\delta}\left(p_{t} Y\right)^{\gamma}\left(e_{i_{t}^{*}}+\sum_{j \neq i_{t}^{*}} \sigma_{j}\left(y_{t}^{*}\right)\right)-e_{i_{t}^{*}}^{2}\right] \\
& +\delta V_{t}^{*}\left(y_{t+1}^{*}\right) .
\end{aligned}
$$

In this class conflict environment the MPE policy and effort rules are unique. They can be constructed directly from the Euler equations. The Euler equations in policy and effort computed from (5) and (7), respectively, imply

$$
p_{t}=\left(\frac{\delta}{(1-\delta)} \frac{\gamma Y^{\gamma} E}{y_{t}^{*}}\right)^{1 /(1-\gamma)} \text { and } e_{i}=\frac{\delta}{(1-\delta)} \frac{(p Y)^{\gamma}}{2} .
$$

From these, the MPE policy and effort (resp.) strategies are easily computed to be

$$
\begin{aligned}
\psi\left(y_{t}^{*}\right) & =A y_{t}^{* 1 /(2 \gamma-1)} \\
\sigma_{i}\left(y_{t}^{*}\right) & =B y_{t}^{* \gamma /(2 \gamma-1)},
\end{aligned}
$$

\footnotetext{
${ }^{8}$ Two comments are worth noting here. First, given separability between public and private consumption, the current stock $\omega_{t}$ of the public good is not relevant to anyone's current decision and may therefore be excluded from the current state. Second, by the well-known One-shot Deviation Principle, Markov strategies are best responses, in the class of all strategies, to other Markov strategies.
} 
where $A$ and $B$ are the positive constants:

$$
A=\left(\frac{2(1-\delta)^{2}}{n \gamma \delta^{2} Y^{2 \gamma}}\right)^{1 /(2 \gamma-1)} \quad \text { and } \quad B=\frac{\delta Y^{\gamma}}{2(1-\delta)} A^{\gamma} .
$$

Conditions (6) show how equilibrium effort and policy choices depend on the wealth of the decision maker. When $\gamma<\frac{1}{2}$ both are decreasing in $y$, and when $\gamma>\frac{1}{2}$ they are both increasing in $y$. Thus when the productivity of spending on the public good falls quickly $\left(\gamma<\frac{1}{2}\right)$ wealthier individuals prefer lower tax rates, but if it falls more slowly $\left(\gamma>\frac{1}{2}\right)$, it is the less wealthy who prefer lower tax rates. Also, transferring power to a less wealthy individual will induce individuals to supply more effort in the first case $\left(\gamma<\frac{1}{2}\right)$, but it deters effort in the second case $\left(\gamma>\frac{1}{2}\right)$.

The direction in which the transfer of power proceeds, if at all, depends on whether, in a given state, equilibrium efforts are too small or too large, according to the current decision maker. Suppose for example that the decision maker could choose the efforts of all individuals directly, as well as the policy instrument, taking into consideration only the cost of his own effort. The decision maker's Bellman equation would be

$$
\left.U_{i}\left(y_{t}^{*}\right)=\max _{e_{t}, p_{t}}\left[y_{t}^{*}\left(1-p_{t}\right)+\frac{\delta}{1-\delta}\left(p_{t} Y\right)^{\gamma} n e_{t}^{*}-e_{t}^{* 2}\right]+\delta U_{i}\left(y_{t+1}^{*}\right)\right) .
$$

From this, the optimal effort of the representative citizen is calculated to be

$$
e_{t}^{*}=\frac{1}{n^{1 /(2 \gamma-1)}} B y_{t}^{* \gamma /(2 \gamma-1)} .
$$

Comparing this condition with the second line of (6), we find $e_{t}^{*}>\sigma_{i}\left(y_{t}^{*}\right)$ if $\gamma<\frac{1}{2}$, while $e_{t}^{*}<\sigma_{i}\left(y_{t}^{*}\right)$ if $\gamma>\frac{1}{2}$. From the perspective of the current decision maker, equilibrium efforts are inefficiently low when $\gamma<\frac{1}{2}$, but inefficiently high when $\gamma>\frac{1}{2}$. This dichotomy can be understood by distinguishing between the classic free-rider problem in the supply of effort by all individuals on the one hand, and the strategic complementarity of policy and effort on the other.

The free-rider problem between individuals in the supply of effort$i$ 's effort is a perfect substitute for $j$ 's - means effort choices are too low. However, if we consider the non-cooperative choice of effort and policy, effort can be too high. Indeed, effort (chosen by individual $j$, say) and policy (chosen by the current decision maker, $i^{*}$ ) are strategic complements, so tend to be oversupplied in equilibrium. The combination of these two effects determines the net equilibrium effort choice. 
The strength of the complementarity between the tax rate and effort is determined by $\gamma$. When taxes (i.e., spending on the public good) and effort are highly complementary $\left(\gamma>\frac{1}{2}\right)$, the strategic oversupply effect dominates the free-rider effect, and effort is too high in equilibrium. On the other hand, when the extent of complementarity is small, the free-rider effect dominates, and effort is too low.

This discussion suggests that in both cases, $\gamma<\frac{1}{2}$ and $\gamma>\frac{1}{2}$, the current decision maker will have an incentive to delegate future authority to an individual with lower wealth: when $\gamma<\frac{1}{2}$, effort is too low in equilibrium and if authority is transferred to an individual with lower wealth equilibrium effort increases; and when $\gamma>\frac{1}{2}$, effort is too high, and transferring power, again to those with lower wealth, reduces it. We confirm this intuition formally in the following.

Every MPE generates a particular sequence of policy makers, $i_{1}^{*}, i_{2}^{*}, \ldots$, through the choice of endowments, $y_{1}^{*}=\mu\left(y_{0}^{*}\right), y_{2}^{*}=\mu\left(y_{1}^{*}\right)$, and so on, where $\mu$ is the rule-of-succession. If it is the case that $y_{0}^{*}>y_{1}^{*}>y_{2}^{*}>\ldots$, that is, successors are always chosen from lower social classes than that of the current policy maker, then we will call this a downward ruleof-succession. Similarly, if $y_{0}^{*}<y_{1}^{*}<y_{2}^{*}<\ldots$, then $\mu$ will be called an upward rule-of-succession. Naturally, the rule-of-succession need not be either strictly upward or downward.

Proposition 1. If $\gamma \neq \frac{1}{2}$, then there is a unique MPE in which $\mu$ is a downward rule-of-succession of the form $\mu\left(y_{t}^{*}\right)=C y_{t}^{*}$ with $0<C<1$.

The result asserts a unique MPE in which the rule-of-succession is downward and linear. Beginning with $y_{0}^{*}$, succession converges to $y$, the lowest endowment. In other words, over time, policy reflects the preferences of the lowest-wealth citizen. The rule-of-succession is displayed in Figure 1.

The result is verified by explicitly constructing the MPE rule-ofsuccession as follows. Let $y_{1}^{*}, y_{2}^{*}, \ldots$ be a hypothesized equilibrium path of land endowments of the policy makers starting from an arbitrary $y_{0}^{*}$. Using the MPE policy and effort strategies in (6), we rewrite the objective function using the Bellman equation (5) from period $t=1$ onward as

$$
\begin{aligned}
V_{0}^{*}\left(y_{0}^{*}\right)= & \sum_{t=1}^{\infty} \delta^{t-1}\left[y_{0}^{*}\left(1-A y_{t}^{* 1 /(2 \gamma-1)}\right)\right. \\
& \left.+\frac{\delta}{1-\delta}\left(A y_{t}^{* 1 /(2 \gamma-1)}\right)^{\gamma} Y^{\gamma} n\left(B y_{t}^{* \gamma /(2 \gamma-1)}\right)-\left(B y_{t}^{* \gamma /(2 \gamma-1)}\right)^{2}\right] \\
= & \sum_{t=1}^{\infty} \delta^{t-1}\left[y_{0}^{*}-y_{0}^{*} A y_{t}^{* 1 /(2 \gamma-1)}+\frac{(n-1 / 2) \delta^{2}}{2(1-\delta)^{2}} A^{2 \gamma} Y^{2 \gamma} y_{t}^{* 2 \gamma /(2 \gamma-1)}\right] .
\end{aligned}
$$




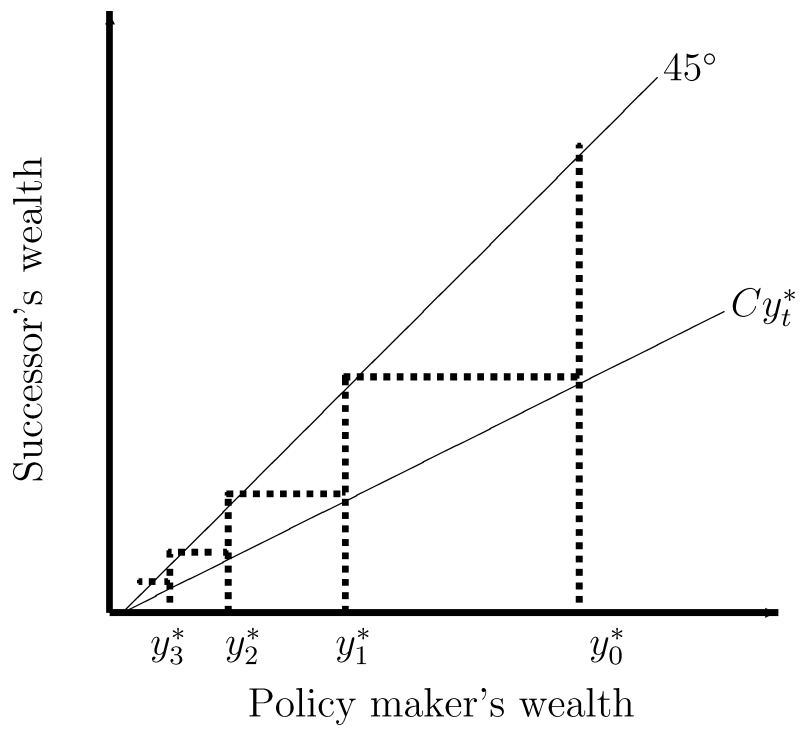

Fig. 1. Downward rule-of-succession under class conflict

The second equality utilizes the expression for $B$ in (7). Recall that a policy maker of type $y_{0}^{*}$ only chooses $y_{1}^{*}$ directly. The choice of $y_{1}^{*}$ then accounts indirectly for future values $y_{t}^{*}, t>1$. In order to make this effect explicit, we verify a "guess" that there exists a linear, downward-sloping MPE rule-of-succession. Specifically, verify $y_{t+1}^{*}=C y_{t}^{*}$ with $0<C<1$. Given this form, and given the constant $B$ in (7), the Bellman equation, (9) may be expressed as

$$
\sum_{t=0}^{\infty} \delta^{t}\left[y_{0}^{*}-y_{0}^{*} A\left(C^{t} y_{1}^{*}\right)^{1 /(2 \gamma-1)}+\frac{(n-1 / 2) \delta^{2}}{2(1-\delta)^{2}} A^{2 \gamma} Y^{2 \gamma}\left(C^{t} y_{1}^{*}\right)^{2 \gamma /(2 \gamma-1)}\right] .
$$

The Euler equation in $y_{1}^{*}$ is given by

$$
\frac{\partial}{\partial y_{1}^{*}}[\cdot]=0,
$$

where [·] is the expression on the RHS of (10). Solving for $y_{1}^{*}$ in the Euler equation gives

$$
y_{1}^{*}=\frac{(1-\delta)^{2}\left(1-\delta C^{2 \gamma /(2 \gamma-1)}\right)}{(n-1 / 2) \gamma \delta^{2} A^{2 \gamma-1} Y^{2 \gamma}\left(1-\delta C^{1 /(2 \gamma-1)}\right)} y_{0}^{*}
$$


provided that $\delta C^{1 /(2 \gamma-1)}<1$. Our guess is verified if there is a unique $C$ such that $\delta C^{1 /(2 \gamma-1)}<1$ and $C$ is the implicit solution to

$$
C=\frac{(1-\delta)^{2}\left(1-\delta C^{2 \gamma /(2 \gamma-1)}\right)}{(n-1 / 2) \gamma \delta^{2} A^{2 \gamma-1} Y^{2 \gamma}\left(1-\delta C^{1 /(2 \gamma-1)}\right)} .
$$

Substituting the expression for $A$ in (7), this implicit equation reduces to

$$
C=\frac{n}{2 n-1}+\frac{n-1}{2 n-1} \delta C^{2 \gamma /(2 \gamma-1)} .
$$

We verify that a unique implicit solution to (11) exists. Observe that the LHS of (11) is the identity function in $C$, while the RHS is a function whose value is strictly above 0 at $C=0$ and is below 1 at $C=1$. Hence, by the Intermediate Value Function, the functions cross at some value of $C$ between 0 and 1 . Moreover, if $\gamma<\frac{1}{2}$, then the RHS is strictly decreasing, and so the functions intersect only once at some $0<C<1$. If $\gamma>\frac{1}{2}$, then they intersect twice with a second intersection at some $C>1$. However, the second intersection violates the requirement, $\delta C^{1 /(2 \gamma-1)}<1$.

\section{Discussion}

The intuition is the following. Recall that externalities exist and that their direction depends on whether $\gamma>\frac{1}{2}$ or $\gamma<\frac{1}{2}$. If $\gamma<\frac{1}{2}$, effort externalities are positive. This means that free riding occurs in equilibrium, i.e., contributions are inefficiently small. But in the $\gamma<\frac{1}{2}$ case, wealthy policy makers, i.e., those with higher land endowments, choose lower tax rates. A wealthy policy maker is therefore better off delegating decision authority to a successor with a lower land endowment. Correctly anticipating that the low land endowment type chooses higher tax rates, the citizens increase their contributions. Hence, delegation to a lower socio-economic class mitigates the free-rider problem.

Conversely, recall that if $\gamma>\frac{1}{2}$ effort externalities are negative. This means that in equilibrium, "reverse free riding" occurs, i.e., contributions are inefficiently large. But because wealthier policy makers choose higher tax rates, a high-endowment individual can, by strategically delegating decision authority to a poorer type, induce appropriately smaller contributions. Hence, delegation of authority to a lower endowment type can again improve the high type's payoff.

In each case, the policy maker is better off by delegating downward. Clearly a high-endowment policy maker loses something in the delegation decision. Namely, his successor chooses an inferior tax rate from the current 
policy maker's point of view. The policy maker gains something, however. His delegation decision partly internalizes the externalities in voluntary contributions.

Clearly the preferred alternative of a date $t$ policy maker would be to commit to a sequence of policies in advance. Unfortunately, this is not feasible, and so a "second-best" alternative is to relinquish power. The delegation of decision-making authority is in itself a form of commitment, but not nearly as effective as committing to a policy sequence. By delegating decision authority to a successor, there is no guarantee that the successor will not delegate further.

In fact, this is precisely what happens: a successor with endowment $y_{1}^{*}$ delegates further to a successor with an even smaller endowment $y_{2}^{*}$, and so on. Accounting for this fact leads the current policy maker to temper his decision. He is more conservative in the designation of a successor than he otherwise would be if his choice were permanent. This "conservatism" therefore slows the process of change, making it more gradual.

The recursive structure of our problem therefore implies the gradual political succession. The gradualism arises from the recursive structure, which is precisely what distinguishes the present approach, and some of our previous work, from most dynamic delegation models in the literature.

\section{Succession Based on Ideological Conflict}

Now assume that all decision makers differ only by ideology. In particular, we assume away class conflicts. Citizens' endowments satisfy $y_{i}=y$ for all $i$, and taste parameters in (2) satisfy $\alpha_{i} \neq \alpha_{j}$ for all $i, j$. Assume $\underline{\alpha}>0$ and denote the aggregate valuation of the public good by $\mathcal{A}=\sum_{i} \alpha_{i}$. The distinct marginal valuations of each citizen induce differences in the way that time trade-offs are viewed. Conflict is therefore driven by differences in ideologies.

Without loss of generality, associate each policy maker $i_{t}^{*}$ with his taste parameter $\alpha_{t}^{*}$. A policy maker $i_{t}^{*}$ therefore chooses pair $\left(p_{t}, \alpha_{t+1}^{*}\right)$. The initial policy maker has taste parameter $\alpha_{0}^{*}$.

When differences are ideological rather than wealth based, Markov strategies must condition on the taste parameter, $\alpha_{t}^{*}$, of the current policy maker. We keep the same notation for Markov strategies so as to not complicate things further. Hence, Markov strategies are, as before, given by $(\sigma, \psi, \mu)$ where, in this case, labor effort, $e_{i t}=\sigma_{i}\left(\alpha_{t}^{*}\right)$ is chosen by Citizen $i$ given the state $\alpha_{t}^{*}$. Similarly, $p_{t}=\psi\left(\alpha_{t}^{*}\right)$ is the chosen policy, while $\alpha_{t+1}^{*}=\mu\left(\alpha_{t}^{*}\right)$ determines the successor who serves as policy maker next period. 
MPE are defined as before, where the Bellman equations are now given by

$$
\begin{aligned}
U_{i}\left(\alpha_{t}^{*}\right)= & \max _{e_{i}}\left[y\left(1-\psi\left(\alpha_{t}^{*}\right)\right)\right. \\
& \left.+\frac{\delta \alpha_{i}}{1-\delta}\left(\psi\left(\alpha_{t}^{*}\right) Y\right)^{\gamma}\left(e_{i}+\sum_{j \neq i} \sigma_{j}\left(\alpha_{t}^{*}\right)\right)-e_{i}^{2}\right]+\delta U_{i}\left(\mu\left(\alpha_{t}^{*}\right)\right)
\end{aligned}
$$

and

$$
\begin{aligned}
V_{t}^{*}\left(\alpha_{t}^{*}\right)= & \max _{p_{t}, \alpha_{t+1}^{*}}\left[y\left(1-p_{t}\right)+\frac{\delta \alpha_{t}^{*}}{1-\delta}\left(p_{t} Y\right)^{\gamma}\left(e_{i_{t}^{*}}+\sum_{j \neq i_{t}^{*}} \sigma_{j}\left(\alpha_{t}^{*}\right)\right)-e_{i_{t}^{*}}^{2}\right] \\
& +\delta V_{t}^{*}\left(\alpha_{t+1}^{*}\right) .
\end{aligned}
$$

As with the case of class conflict, the MPE rules for policy and effort are unique and may be computed directly from Euler equations derived from (12) and (13). These MPE rules are:

$$
\begin{aligned}
& \psi\left(\alpha_{t}^{*}\right)=\bar{A} \alpha_{t}^{* 1 /(1-2 \gamma)} \\
& \sigma_{i}\left(\alpha_{t}^{*}\right)=\overline{B_{i}} \alpha_{t}^{* \gamma /(1-2 \gamma)},
\end{aligned}
$$

where $\bar{A}$ and $\bar{B}$ are the positive constants

$$
\bar{A}=\left(\frac{2(1-\delta)^{2}}{\mathcal{A} \gamma \delta^{2} Y^{2 \gamma}} y\right)^{1 /(2 \gamma-1)} \quad \text { and } \quad \bar{B}_{i}=\alpha_{i} \frac{\delta Y^{\gamma}}{2(1-\delta)} \bar{A}^{\gamma} .
$$

Note that the form of the MPE effort and policy rules are almost identical to that of class conflict with one key difference. The monotone direction is reversed. As before, the cases of $\gamma<\frac{1}{2}$ and $\gamma>\frac{1}{2}$ determine the degree to which policy and effort are substitutes or complements in the dynamic objective functions of citizens. Here, however, if $\gamma>\frac{1}{2}$, then policy and effort are decreasing functions of the valuation of the public good, whereas if $\gamma<\frac{1}{2}$, then policy and effort are increasing in the valuation.

It remains true that policy and effort are net substitutes if $\gamma<\frac{1}{2}$ and are net complements if $\gamma>\frac{1}{2}$. But the effects of complements and substitutes work differently for valuations than for endowments. Observe that a representative citizen with valuation $\alpha_{t}^{*}$ would assign to each citizen effort level,

$$
e_{t}^{* *}=\frac{1}{n^{1 /(2 \gamma-1)}} \bar{B} \alpha_{t}^{* \gamma /(1-2 \gamma)} .
$$

In particular, the efficient effort level is the same as in the class conflict case if $1 / \alpha_{t}^{*}=y_{t}^{*}$. In this case, equilibrium effort is too high when $\gamma>\frac{1}{2}$ 


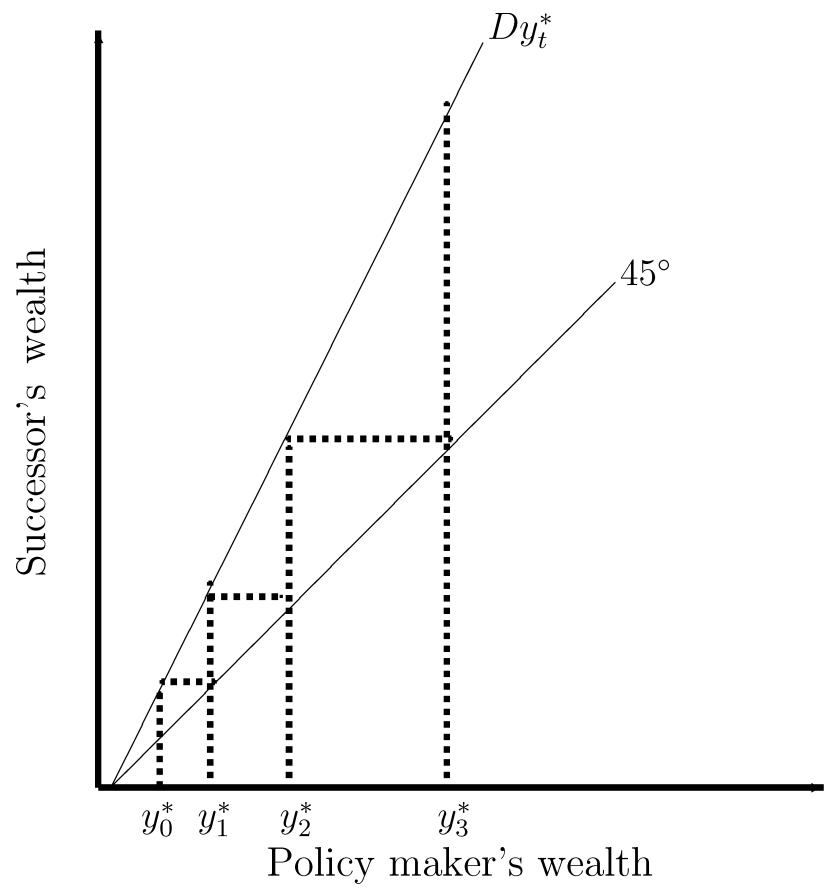

Fig. 2. Upward rule-of-succession under ideological conflict

since individuals overcompensate for lower taxes. Conversely, equilibrium effort is too low when $\gamma>\frac{1}{2}$ since individuals fail to internalize the positive effects of others' contributions.

As with land endowments, $\mu$ is a downward rule-of-succession if the equilibrium path satisfies $\alpha_{0}^{*}>\alpha_{1}^{*}>\ldots$, and is an upward rule-ofsuccession if the reverse strict ordering obtains.

Proposition 2. If $\gamma \neq \frac{1}{2}$, then there is a unique MPE in which $\mu$ is an upward rule-of-succession of the form $\mu\left(\alpha_{t}^{*}\right)=D \alpha_{t}^{*}$ with $D>1$.

The result asserts a very different conclusion than that of class conflict. When the source of the conflict is ideological, then there is a unique equilibrium in which the rule-of-succession is upward and linear. Beginning with $\alpha_{0}^{*}$, succession converges to $\bar{\alpha}$, the highest valuation for the public good. In other words, over time, policy eventually reflects the preferences of the highest valuation citizen. This rule-of-succession is displayed in Figure 2.

The proof is very similar to that of class conflict. As with that case, the construction is explicit. Let $\alpha_{1}^{*}, \alpha_{2}^{*}, \ldots$ be a hypothesized equilibrium path. Using the MPE policy and effort rules, the policy maker's objective 
function for the designated successor, using the Bellman equation (13) from period $t=1$ onward is

$$
\begin{aligned}
V_{0}^{*}\left(\alpha_{1}^{*}\right)= & \sum_{t=1}^{\infty} \delta^{t-1}\left[y\left(1-\bar{A} \alpha_{t}^{* 1 /(1-2 \gamma)}\right)\right. \\
& \left.+\alpha_{0}^{*} \frac{\delta}{1-\delta}\left(\bar{A} \alpha_{t}^{* 1 /(1-2 \gamma)}\right)^{\gamma} Y^{\gamma} \mathcal{A}\left(\bar{B} \alpha_{t}^{* \gamma /(1-2 \gamma)}\right)-\left(\bar{B} \alpha_{t}^{* \gamma /(1-2 \gamma)}\right)^{2}\right] \\
= & \sum_{t=1}^{\infty} \delta^{t-1}\left[y-y \bar{A} \alpha_{t}^{* 1 /(1-2 \gamma)}+\alpha_{0}^{*} \frac{(\mathcal{A}-1 / 2) \delta^{2}}{2(1-\delta)^{2}} \bar{A}^{2 \gamma} Y^{2 \gamma} \alpha_{t}^{* 2 \gamma /(2 \gamma-1)}\right] .
\end{aligned}
$$

Recall that a policy maker of type $\alpha_{0}^{*}$ only chooses $\alpha_{1}^{*}$ directly. We use the same "guess and verify" method as before: we guess a rule-of-succession of the form $\alpha_{t+1}^{*}=D \alpha_{t}^{*}$. To be an upward rule-of-succession, we posit-and verify - that $D>1$. Substituting in the constants from (15), and recalling that $\sum_{j} \alpha_{j}=\mathcal{A}$ is the aggregate valuation, the Euler equation in $\alpha_{1}^{*}$ reduces to

$$
\alpha_{1}^{*}=\left(\frac{2 \mathcal{A}-1}{\mathcal{A}}\right) \frac{1-\delta D^{1 /(1-2 \gamma)}}{1-\delta D^{2 \gamma /(1-2 \gamma)}}
$$

provided that $\delta D^{1 /(2 \gamma-1)}<1$. Our guess is verified if there is a unique $D$ such that $\delta D^{1 /(2 \gamma-1)}<1$ and $D$ is the implicit solution to

$$
D=\left(\frac{2 \mathcal{A}-1}{\mathcal{A}}\right) \frac{1-\delta D^{1 /(1-2 \gamma)}}{1-\delta D^{2 \gamma /(1-2 \gamma)}}
$$

or

$$
D=\frac{2 \mathcal{A}-1}{\mathcal{A}}-\left(\frac{\mathcal{A}-1}{\mathcal{A}}\right) \delta D^{1 /(1-2 \gamma)} .
$$

Note that if the $\alpha_{i}$ are normalized so that $A=1$, and if $C^{*}$ solves (11), then $D^{*}=1 / C^{*}$ solves (17)-i.e., the coefficient on the ideological ruleof-succession is the reciprocal of the coefficient on the class-based rule-ofsuccession.

All that is left is to verify that a unique implicit solution to (17) exists satisfying $\delta D^{1 /(2 \gamma-1)}<1$ and that this solution entails $D>1$. Observe that the LHS of (17) is the identity function in $D$, while the RHS is a decreasing function if $\gamma<\frac{1}{2}$ and increasing if $\gamma>\frac{1}{2}$. If $\gamma<\frac{1}{2}$, then the right-side function has value of 2 at $D=0$ and has negative values for $D$ large enough. The Intermediate Value Theorem (IVT) therefore implies a unique intersection. Since the RHS exceeds 1 at $D=1$, it follows that the intersection occurs at $D>1$. If $\gamma>\frac{1}{2}$, then the right-side function is $-\infty$ at $D=0$ and asymptotes to 2 as $D$ becomes large. Again IVT implies an 
intersection. In fact, the right-hand function intersects the $45^{\circ}$-line twice, once at $D<1$ and another at $D>1$. Only the larger solution of $D>1$ satisfies $\delta D^{1 /(2 \gamma-1)}<1$.

\section{Discussion}

The intuition is the following. As before, externalities in effort lead to inefficient contributions. However, here the externalities work in reverse. If $\gamma<\frac{1}{2}$, effort externalities are positive, and so contributions are inefficiently small. But because policy makers with lower marginal valuation choose lower tax rates than those with higher valuations, strategic delegation of authority to a higher valuation type can improve the low type's payoff.

Conversely, if $\gamma>\frac{1}{2}$ effort externalities are negative, and so contributions are inefficiently large. But because policy makers with lower marginal valuation choose higher tax rates than those with higher valuations, strategic delegation of authority to a higher valuation type can again improve the low type's payoff.

As before, full commitment to an infinite sequence of policies is not feasible, and so strategic delegation to a successor is the "second-best" alternative. Just as before, the continued delegation by future successors to their successors induces conservatism in the choice of the present policy maker. Hence, the process is gradual.

\section{Class and Ideology}

Both sources of conflict may be combined. Using the same type of Euler equation derivations, the unique Markov-perfect equilibrium (MPE) can be expressed in terms of a composite state variable:

$$
\beta_{i}=\frac{y_{i}}{\alpha_{i}} .
$$

This state expresses the income value of the public good to a Citizen $i$ whose land endowment is $y_{i}$. $\beta_{t}^{*}$ is the public good desired by policy maker $i_{t}^{*}$. The MPE policies and efforts rules are:

$$
\begin{aligned}
& \psi\left(\beta_{t}^{*}\right)=A^{*} \beta_{t}^{* 1 /(2 \gamma-1)} \\
& \sigma_{i}\left(\alpha_{t}^{*}\right)=B^{*} \beta_{t}^{* \gamma /(2 \gamma-1)},
\end{aligned}
$$

where $A^{*}$ and $B^{*}$ are the positive constants

$$
A^{*}=\left(\frac{2(1-\delta)^{2}}{\mathcal{A} \gamma \delta^{2} Y^{2 \gamma}}\right)^{1 /(2 \gamma-1)} \quad \text { and } \quad B_{i}^{*}=\alpha_{i} \frac{\delta Y^{\gamma}}{2(1-\delta)} A^{* \gamma},
$$

and the MPE rule-of-succession is $\mu\left(\beta_{t}^{*}\right)=C \beta_{t}^{*}$ where $C<1$ and is the same $C$ that implicitly solved (11) in the class conflict case. 


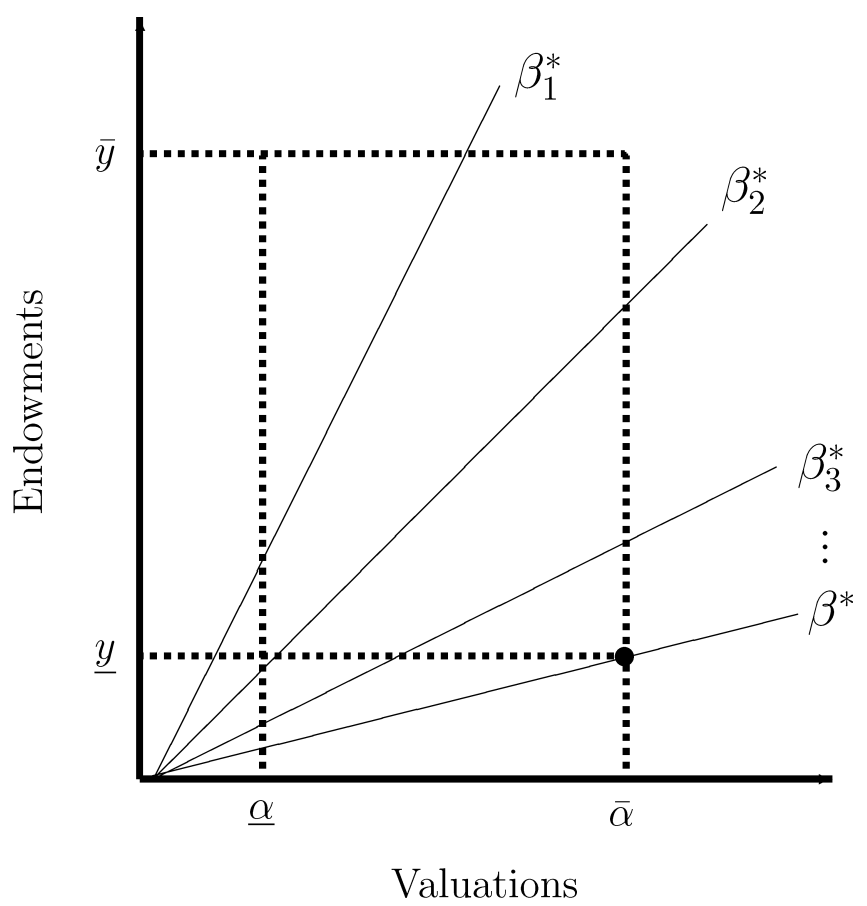

Fig. 3. Rule-of-succession converges to $\beta^{*}$

Suppose, first, that policy makers can be drawn from all possible values in $[y, \bar{y}] \times[\underline{\alpha}, \bar{\alpha}]$. Then Propositions 1 and 2 imply that the rule-ofsuccession converges to the $\beta^{*}$ satisfying $\beta=\underline{y} / \bar{\alpha}$. That is, succession proceeds until the chosen policy maker is the one from the lowest economic class who, at the same time, has the highest marginal valuation for the public good. Figure 3 displays this case. In it, equivalence classes of decision makers consist of different types along an equation $y=\beta \alpha$. These are all citizens whose ratio of wealth to valuation of the public good is the same. The downward rule-of-succession implies that this society gradually delegates to the policy maker with characteristics, $(y, \bar{\alpha})$.

This is not an unreasonable scenario in cases where the policy maker is a median voter, and succession corresponds to voting over expansion of voting franchise. Arguably, the progressive expansions in nineteenth-century Western Europe were made to lower socio-economic groups with a greater preference for an expanded welfare state.

A more likely scenario is one in which class and ideology are correlated. Naturally, this depends on the type of public good. Public transportation and public health insurance are examples of public goods preferred most likely 


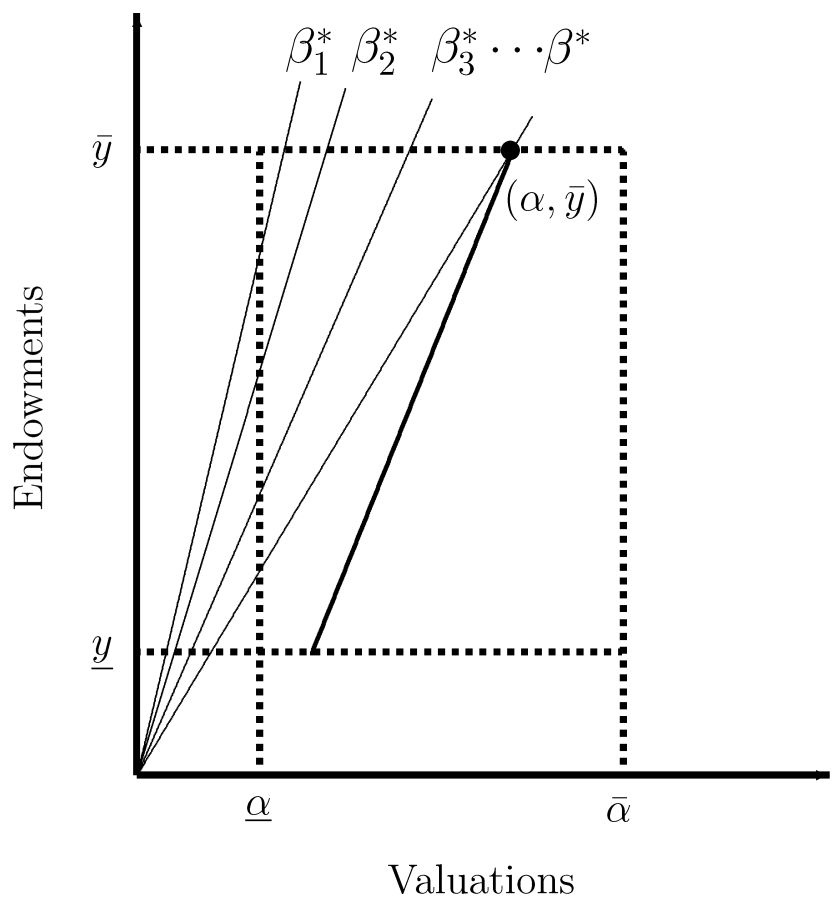

Fig. 4. Perfectly correlated types and convergence to $\beta^{*}$

by poorer citizens, whereas interstate highways, art museums and national defense (because the rich have more to lose) are examples of public goods most likely preferred by wealthier citizens. Figure 4, in which all citizens are located on the bold line, displays one form of perfect correlation between wealth levels and marginal valuations. The nature of the correlation is such that the MPE path converges to a pair $(\alpha, \bar{y})$ so that the policy maker remains in the highest social class. Alternatively, if the correlation between income and valuation of public goods is negative, over time the identity of the policy maker evolves towards having relatively low wealth and moderate public good preferences (depending on the precise relationship between the two parameters, reflected in the slope of the bold line in Figure 4).

Finally, consider the case of imperfect correlation, expressed in terms of a limited support in the shape of a lens in Figure 5. In that case, the dynamics of the MPE rule-of-succession converges to some interior $(\alpha, y)$ corresponding to the tangency of an equivalence class of types and the boundary of the support. 


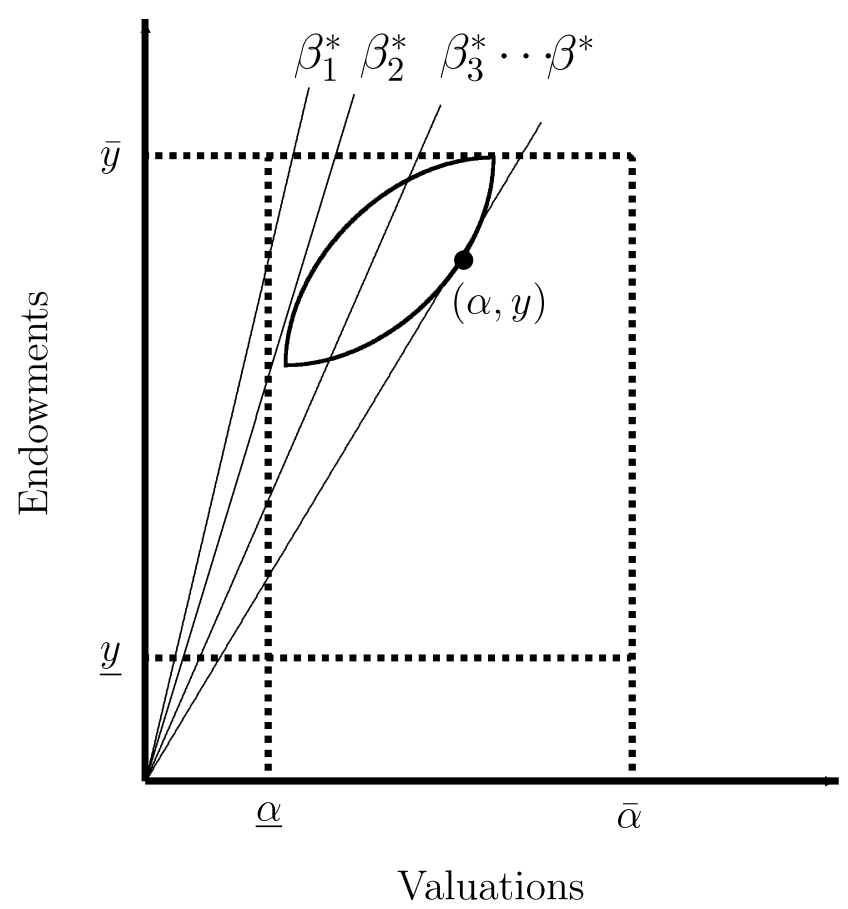

Fig. 5. Correlation and smaller support

\section{Concluding Remarks}

This paper examines the nature of rules-of-succession in the face of social conflict. We find that class conflict gives rise to downward rulesof-succession while ideological conflict gives rise to upward rules-ofsuccession.

A question naturally arises as to what "downwardness" and "upwardness" actually mean. In our context, however, the interpretation seems clear. The model posits different sources of conflict that amount to the same thing. Namely, citizens have conflicting evaluations of the trade-off between one's own private wealth and the public good (whatever the latter happens to be). The "downwardness" in social class refers to the natural ordering of wealth endowments. The wealth endowment is simply the marginal cost of contributing toward the public good. The "upwardness" of ideology refers to the ordering on public good valuations. These valuations are simply the marginal benefit that an individual places on the combined use of aggregate wealth and own effort for public purposes.

The model is intended to be suggestive rather than definitive in its predictions for institutional change. A large number of mitigating factors are 
excluded for the sake of tractability. Among the most important is technological progress; specifically, progress that changes either the wealth distribution or the individual trade-offs between public and private goods. Demographic changes also matter. As a society's population density changes, the effects of congestion and urbanization create different needs than those of traditional agrarian societies.

What the model does do is illustrate the effect of a particular set of conflicts, taken in isolation, on a particular set of institutional modifications. We think this exercise has some merit, but enormous amounts of work remain to be done. In their new book, Acemoglu and Robinson (2006) describe idiosyncratic factors in a country's development that help to determine its current political system. Our hope is that models can clarify precisely the nature of these factors. We foresee a broad need for future modeling along these lines.

\section{References}

Acemoglu, D. and Robinson, J. (2000), Why Did the West Extend the Franchise? Democracy, Inequality and Growth in Historical Perspective, Quarterly Journal of Economics 115, $1167-1199$.

Acemoglu, D. and Robinson, J. (2001), A Theory of Political Transitions, American Economic Review 91, 938-963.

Acemoglu, D. and Robinson, J. (2006), Economic Origins of Dictatorship and Democracy, Cambridge University Press, Cambridge.

Barbera, S., Maschler, M. and Shalev, S. (2001), Voting for Voters: A Model of Electoral Evolution, Games and Economic Behavior 37, 40-78.

Black, D. (1958), The Theory of Committees and Elections, Cambridge University Press, London.

Finer, S. E. (1997), The History of Government, Oxford University Press, Oxford.

Gans, J. and Smart, M. (1996), Majority Voting with Single-crossing Preferences, Journal of Public Economics 59, 219-237.

Gradstein, M. (2003), Political Inequality and Institutional Quality mimeo.

Grandmont, J.-M. (1978), Intermediate Preferences and the Majority Rule, Econometrica 46, $317-330$.

Jack, W. and Lagunoff, R. (2006), Dynamic Enfranchisement, Journal of Public Economics 90, 551-572.

Justman, M. and Gradstein, M. (1999), The Industrial Revolution, Political Transition, and the Subsequent Decline in Inequality in 19th Century Britain, Exploration in Economic History 36, 109-127.

Lagunoff, R. (2005a), Markov Equilibrium in Models of Dynamic Endogenous Political Institutions, mimeo, Georgetown University, www.georgetown.edu/faculty/lagunofr/dynampolit-b.pdf.

Lagunoff, R. (2005b), Dynamic Stability and Reform of Political Institutions, mimeo, Georgetown University, www.georgetown.edu/faculty/lagunofr/dynam-polit.pdf.

Lang, S. (1999), Parliamentary Reform, 1785-1928, Routledge, London.

Lizzeri, A. and Persico, N. (2004), Why Did the Elites Extend the Suffrage? Democracy and the Scope of Government, with an Application to Britain's "Age of Reform", Quarterly Journal of Economics 119, 707-765. 
Roberts, K. (1977), Voting over Income Tax Schedules, Journal of Public Economics 8, 329-340.

Roberts, K. (1998), Dynamic Voting in Clubs, mimeo, STICERD/Theoretical Economics Discussion Paper, London School of Economics.

Roberts, K. (1999), Voting in Organizations and Endogenous Hysteresis, mimeo, Nuffield College, Oxford.

Rothstein, P. (1990), Order Restricted Preferences and Majority Rule, Social Choice and Welfare 7, 331-342. 
